\title{
Effect of Heat Input on Microstructure and Mechanical Properties of Joints Made by Bypass-Current MIG Welding- Brazing of Magnesium Alloy to Galvanized Steel
}

\author{
Yugang Miao $\cdot$ Bintao Wu $\cdot$ Xiangfang Xu $\cdot$ Duanfeng Han
}

Received: 7 January 2014/Revised: 7 March 2014/Published online: 3 August 2014

(C) The Chinese Society for Metals and Springer-Verlag Berlin Heidelberg 2014

\begin{abstract}
Experiments were carried out with bypass-current MIG welding-brazing of magnesium alloy to galvanized steel to investigate the effect of heat input on the microstructure and mechanical properties of lap joints. Experimental results indicated that the joint efficiency tended to increase at first and then to reduce with the increase of heat input. The joint efficiency reached its maximum of about $70 \%$ when the heat input was $155 \mathrm{~J} / \mathrm{mm}$. The metallurgical bonding between magnesium alloy and steel was a thin continuous reaction layer, and the intermetallic compound layer consisted of $\mathrm{Mg}-\mathrm{Zn}$ and slight $\mathrm{Fe}-\mathrm{Al}$ phases. It is concluded that bypass-current MIG welding-brazing is a stable welding process, which can be used to achieve defect-free joining of magnesium alloy to steel with good weld appearances.
\end{abstract}

\section{KEY WORDS: Bypass-current MIG welding-brazing; Dissimilar metals; Joint characteristics; Interface analysis}

\section{Introduction}

Magnesium/steel is a promising composite structural material with wide applications in aerospace vehicles, automobiles, and large military ships because of its excellent properties, such as low weight, high specific strength, and good energy absorption and shielding [1-3]. However, it is still a challenge to join magnesium alloy to steel to achieve excellent mechanical properties, because there are considerable differences between them in metallurgical and physical properties. For example, there is a big difference between them in melting points $\left(649^{\circ} \mathrm{C}\right.$ for $\mathrm{Mg}$, and $1,535^{\circ} \mathrm{C}$ for $\mathrm{Fe}$ ), $\mathrm{Mg}$ and $\mathrm{Fe}$ have nearly zero solubility. Furthermore, $\mathrm{Mg}$ and $\mathrm{Fe}$ do not mix in the liquid

Available online at http://link.springer.com/journal/40195

Y. Miao $\cdot$ B. Wu $\cdot$ X. Xu $\cdot$ D. Han $(\bowtie)$

National Key Laboratory of Science and Technology on

Underwater Vehicle, Harbin Engineering University, Harbin 150001, China

e-mail: handuanfeng@gmail.com state at ambient pressure, there is almost no intersolubility and reaction when magnesium alloy is welded to steel.

Friction stir welding (FSW) $[4,5]$ and resistance spot $[6$, 7] have been considered as the effective joining techniques in joining dissimilar AZ31 Mg to Zn galvanized steel due to the ability to accelerate the diffusion of $\mathrm{Al}$ from base metal $\mathrm{Mg}$ alloys to steel to produce $\mathrm{Fe}-\mathrm{Al}$ phase through the external force and strong stirring action in welding process. Elthalabawy and Khan $[8,9]$ studied the weldability, microstructure, and mechanical properties of diffusion-brazed austenitic stainless steel to magnesium alloy. However, both the welded joints made using these processes do not have satisfactory mechanical properties, and these processes are also limited by the shape and size of workpiece. As reported in Refs. [10-12], an intermediate foil layer or coating was added to join magnesium alloy to steel, but the material in the reaction layer can be easily lost, in the mean time, it is difficult for the magnesium alloy to avoid oxidation in the welding process [13, 14]. The joints of fusion welding can be achieved using laserTIG hybrid welding, but the maximum strength of a welded joint is $<95 \mathrm{MPa}[15,16]$. 
Table 1 Chemical compositions of AZ31B magnesium alloy and Q235 steel (in wt\%)

\begin{tabular}{llllllllll}
\hline Material & $\mathrm{Si}$ & $\mathrm{Fe}$ & $\mathrm{Mn}$ & $\mathrm{Al}$ & $\mathrm{Zn}$ & $\mathrm{C}$ & $\mathrm{Cr}$ & $\mathrm{Ni}$ \\
\hline Q235 & 0.22 & Bal. & 0.48 & 0.45 & - & $0.12-0.2$ & 0.18 & - \\
AZ31B & 0.1 & 0.005 & $0.20-0.50$ & $2.50-3.50$ & $0.50-1.50$ & - & - & 0.005 & Bal. \\
\hline
\end{tabular}
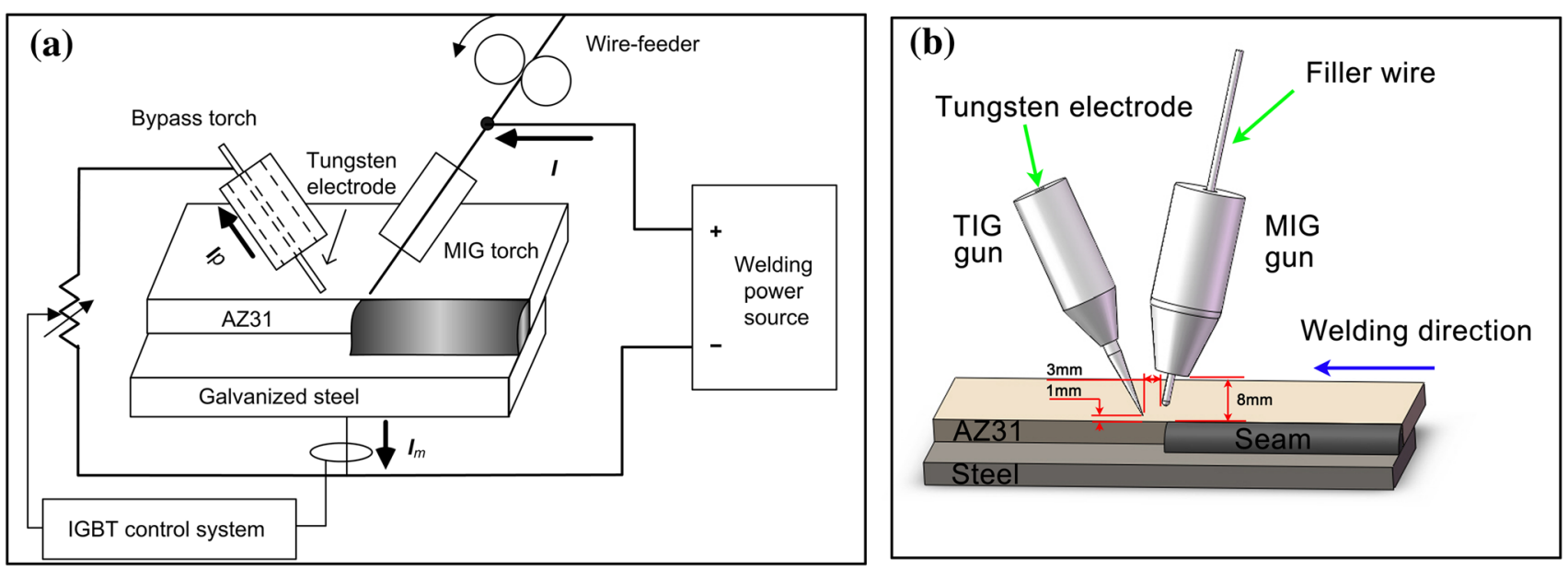

Fig. 1 Schematic diagrams of the BC-MIG process: a block diagram of BC-MIG process; $\mathbf{b}$ welding schematic

Therefore, bypass-current MIG welding-brazing (BCMIG) [17] is proposed to join magnesium alloy to galvanized steel. In the BC-MIG system, the total welding current is decoupled into base metal current and bypass current by adding a bypass torch to a conventional MIG system, which makes it possible to increase the melting wire current while the base metal current is kept at a desired level.

The BC-MIG process has such merits as low heat input, stable arc, and steady droplet transfer, which are essential for the defect-free joining of magnesium alloy to steel. This paper described the effect of heat input on the characteristics of lap joints through comparative study on the formation of $\mathrm{Mg} /$ steel joints under different arc voltages and welding speeds, phase composition and interface microstructure regulation of reaction layer were also investigated by analyzing the composition of welded joints.

\section{Experimental}

Specimens used in the work were $200 \mathrm{~mm} \times 50 \mathrm{~mm}$ in dimensions with Q235 galvanized steel sheet having a thickness of $2 \mathrm{~mm}$ and AZ31 magnesium alloy sheet of $2.5 \mathrm{~mm}$. The chemical compositions of these two metals are tabulated in Table 1. The filler material used was AZ31 magnesium alloy wire with a diameter of $1.6 \mathrm{~mm}$. The grease and impurities attached to $\mathrm{Mg}$ alloy and galvanized
Table 2 Parameters used for different welding experiments

\begin{tabular}{llll}
\hline Experiment & $\begin{array}{l}\text { Welding } \\
\text { voltage }(\mathrm{V})\end{array}$ & $\begin{array}{l}\text { Welding speed } \\
(\mathrm{cm} / \mathrm{min})\end{array}$ & $\begin{array}{l}\text { Heat input }(\mathrm{J} / \\
\mathrm{mm})\end{array}$ \\
\hline A & 18 & 70 & 117 \\
B & 18 & 53 & 155 \\
$\mathrm{C}$ & 19 & 53 & 163 \\
$\mathrm{D}$ & 19 & 65 & 133 \\
\hline
\end{tabular}

There are some constant parameters for all experiments as followings: main current is $76 \mathrm{~A}$; main Gas flow is $15 \mathrm{~L} / \mathrm{min}$; bypass current is 20 A; bypass gas flow is $5 \mathrm{~L} / \mathrm{min}$; TIG tungsten hight is $1 \mathrm{~mm}$; MIG torch height is $8 \mathrm{~mm}$; distance between wire and tungsten is $3 \mathrm{~mm}$

steel were removed with acetone, and the oxidation layer was removed by polishing with emery paper.

As shown in Fig. 1, the total welding current $I$ can be decoupled using non-consumable tungsten electrode into base metal current $I_{\mathrm{m}}$ and bypass current $I_{\mathrm{p}}$ :

$I_{\mathrm{p}}+I_{\mathrm{m}}=\mathrm{I}$,

where $I$ is total welding current $(\mathrm{A}), I_{\mathrm{p}}$ is bypass current (A), and $I_{\mathrm{m}}$ is base metal current (A).

The base metal current $I_{\mathrm{m}}$ can be kept at a desired level by adjusting bypass current $I_{\mathrm{p}}$, while the current of melting filler wire is kept at a high level. Thus, the BC-MIG process can help the reliable joining of magnesium alloy to steel. 

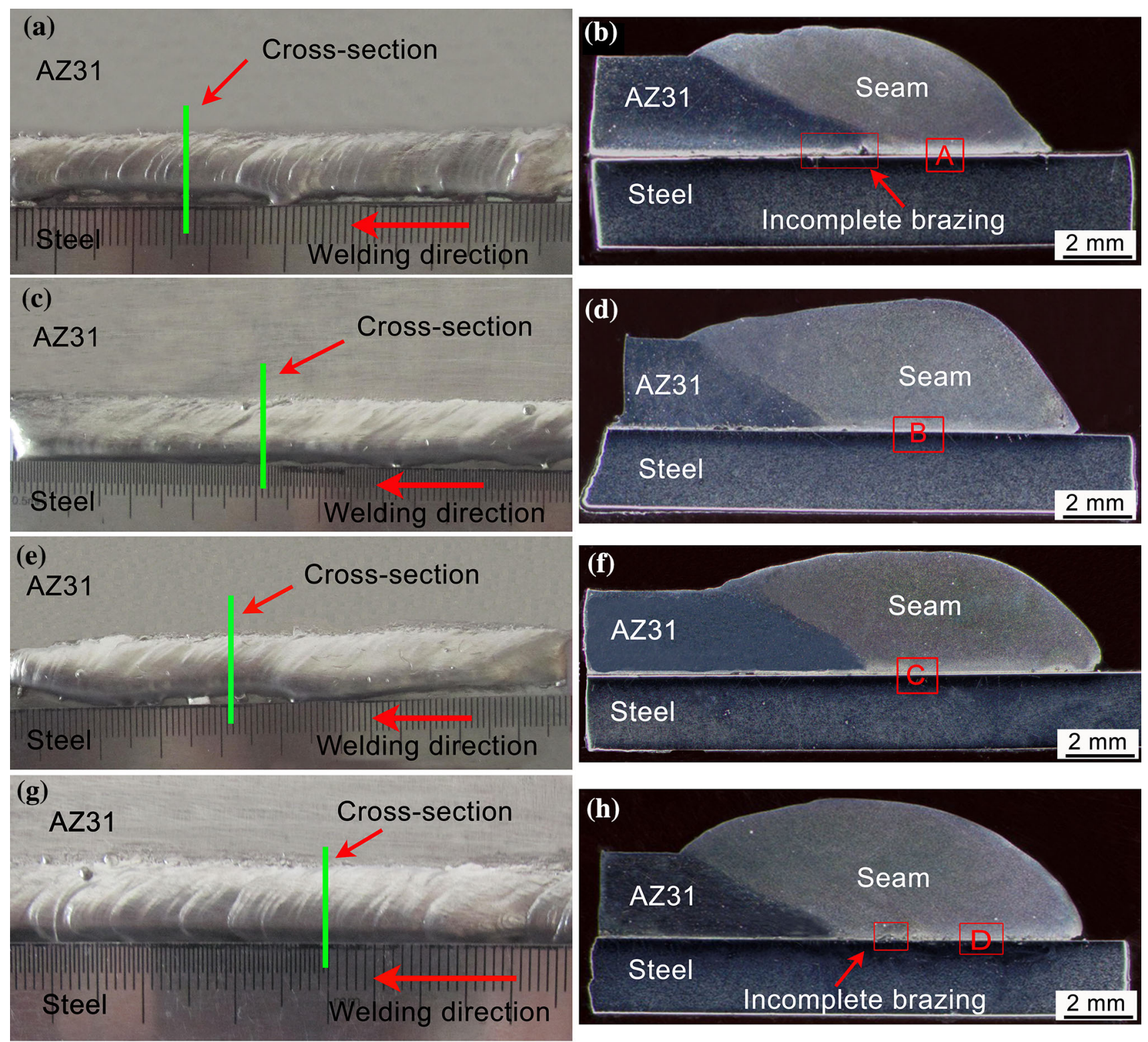

Fig. 2 Weld appearances and cross sections of lap joints at different welding voltages $(U)$ and welding speeds $(v): \mathbf{a}, \mathbf{b} U=18 \mathrm{~V}, v=70 \mathrm{~cm} /$ $\min ; \mathbf{c}, \mathbf{d} U=18 \mathrm{~V}, v=53 \mathrm{~cm} / \mathrm{min} ; \mathbf{e}, \mathbf{f} U=19 \mathrm{~V}, v=53 \mathrm{~cm} / \mathrm{min} ; \mathbf{g}, \mathbf{h} U=19 \mathrm{~V}, v=65 \mathrm{~cm} / \mathrm{min}$

The BC-MIG process was conducted under different welding parameters in this study to find out the effect of heat input on the characteristics of lap joints. These parameters are listed in Table 2. After welded, the specimens were sectioned, ground, and polished. The microstructure and reaction layer of the welded joints were observed using optical microscopy (OM) and scanning electron microscopy (SEM). The distribution of elements was established through energy spectrum analysis (EDS). Micro-hardness tests were carried out along the interface layer of a lap joint with a load of $100 \mathrm{~g}$ and a dwell time of $10 \mathrm{~s}$ on a HXD-1000TM hardness tester. The joint strength was examined on a Zwick/Roell Z010 testing machine with a tensile rate of $2 \mathrm{~mm} / \mathrm{min}$ at a temperature of $20^{\circ} \mathrm{C}$. The fracture behaviors of specimens were observed by SEM.

\section{Results and Discussion}

\subsection{Weld Appearance and Microstructure}

It is observed in Fig. 2 that a smooth and uniform weld appearance was achieved using BC-MIG process. As shown in Fig. 2a, the bead was narrow in width and high in reinforcement when the heat input was $117 \mathrm{~J} / \mathrm{mm}$. An incomplete fusion is exhibited in the interface between 
magnesium alloy and steel (Fig. 2b) because of the poor wetting and spreading due to the relatively low heat input. In Fig. 2c, d, heat input was increased by decreasing welding speed, and complete fusion was achieved on the interface, owning to the desired heat input. However, as shown in Fig. 2e, f, the further increase of heat input can exacerbate the burning of magnesium filler wire and the evaporation of $\mathrm{Zn}$-coating layer to make the welding process unsteady. It is shown in Fig. $2 \mathrm{~g}$ and that incomplete fusion is formed at the interface if the welding speed further increased. In order to form high-quality interface layers, it is very important to maintain a reasonable control of heat input in the whole BC-MIG process.
The stability of welding process was improved by adding a bypass arc, and spatter can hardly be seen in the process. As shown in Fig. 3, the upward rejection of droplet was a typical repelled transfer, which broadened the wetting and spreading area of the droplet, and so the welding quality was improved. It can, therefore, be concluded that the bypass arc not only stabilizes the MIG arc, but also extends the root of the coupling arc. The droplet was eventually completely surrounded so that the droplet was forced to transfer in the direction of an electromagnetic force. In addition, the plasma flow from the upper side to the bottom of the droplet was accelerated by the bypass arc, thereby facilitating the detachment of the droplet from the
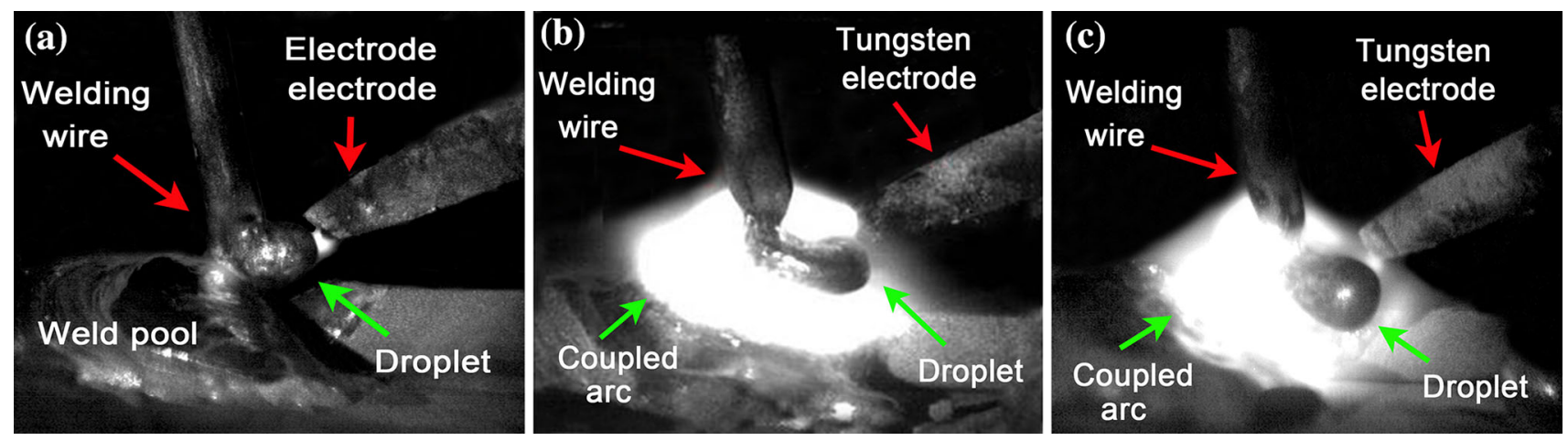

Fig. 3 Droplet transfer in BC-MIG process: a formation of droplet; $\mathbf{b}$ repelled transfer; $\mathbf{c}$ droplet falling
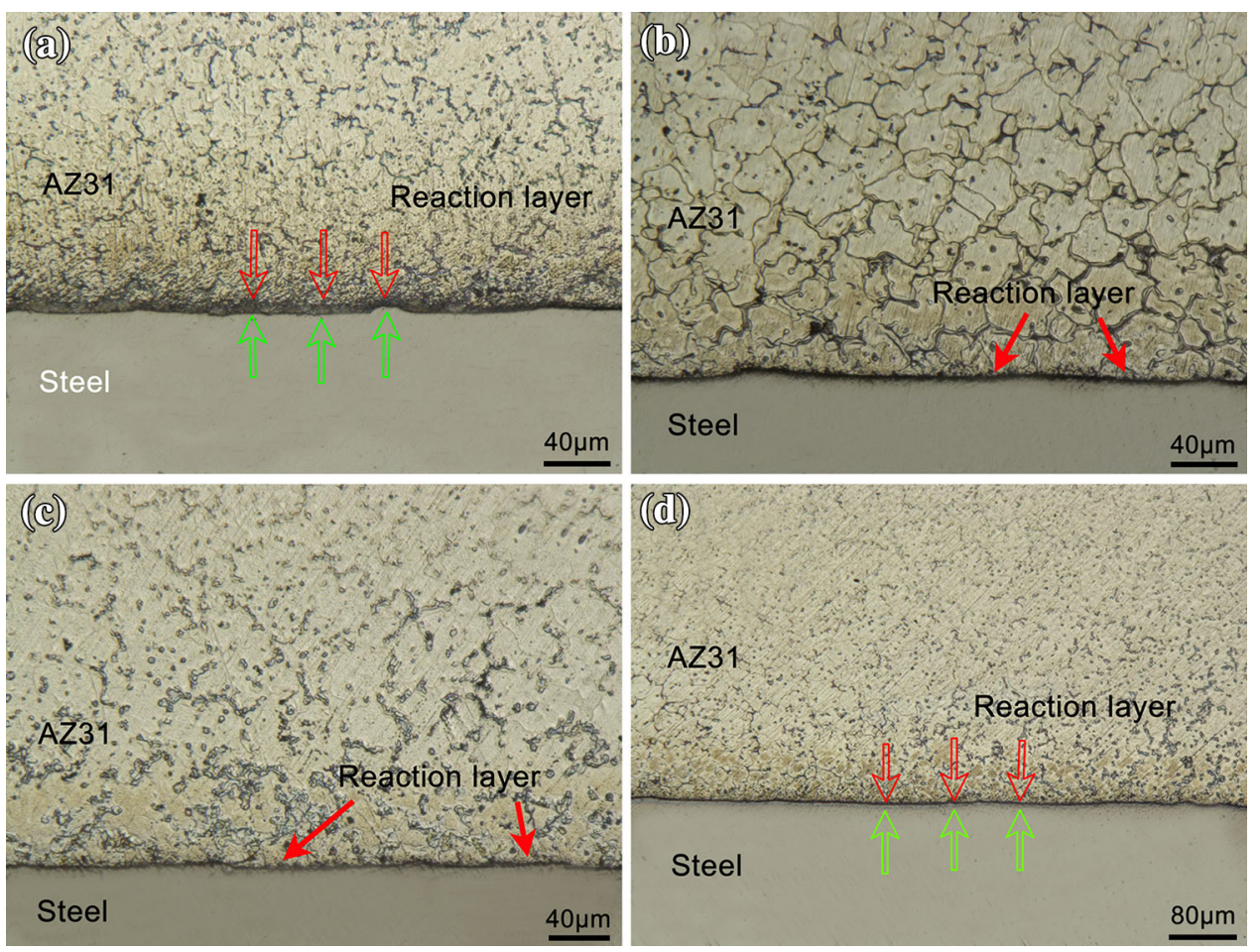

Fig. 4 Interface macrographs of lap joints at different welding voltages $(U)$ and welding speeds $(v): \mathbf{a} U=18 \mathrm{~V}, v=70 \mathrm{~cm} / \mathrm{min} ; \mathbf{b} U=18 \mathrm{~V}$, $v=53 \mathrm{~cm} / \mathrm{min} ; \mathbf{c} U=19 \mathrm{~V}, v=53 \mathrm{~cm} / \mathrm{min} ; \mathbf{d} U=19 \mathrm{~V}, v=65 \mathrm{~cm} / \mathrm{min}$ 

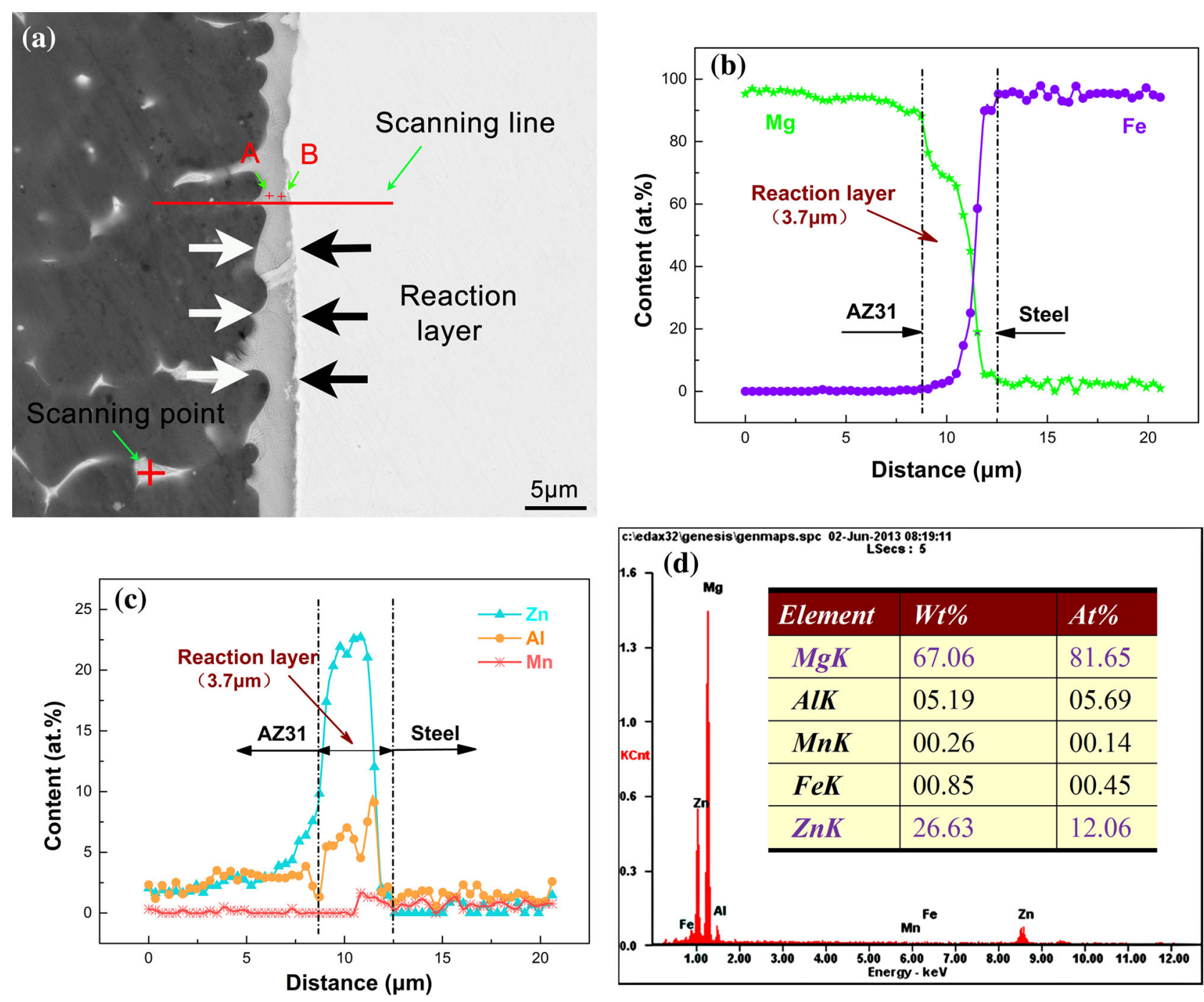

Fig. 5 EDS analysis results of the joint interface: a SEM image of joint interface; b $\mathrm{Mg}$ and Fe distributions along the scanning line; $\mathbf{c} \mathrm{Zn}$, Al, and Mn distributions along the scanning line; $\mathbf{d}$ EDS result of the denoted point

welding wire. The spot force generated by the coupling arc and the reacting force generated by the excessive evaporation of magnesium repelled the transfer of droplet, which prolonged the transfer time of the droplet and the diffusion time among the elements, thereby achieving the full melting and spreading of filler solder.

\subsection{Interface Analysis}

As shown in Fig. 4, the bonding interface was smooth and compact, and no defects were observed on the interface. The melting of lap joints occurred mainly on the side of magnesium alloy, while the melting of steel can hardly be found. A very thin reaction layer is observed on the $\mathrm{Mg} / \mathrm{Fe}$ interface, which is believed to be related to the diffusing or dissolving of alloy elements. As shown in Fig. $4 \mathrm{a}, \mathrm{Mg}$ and

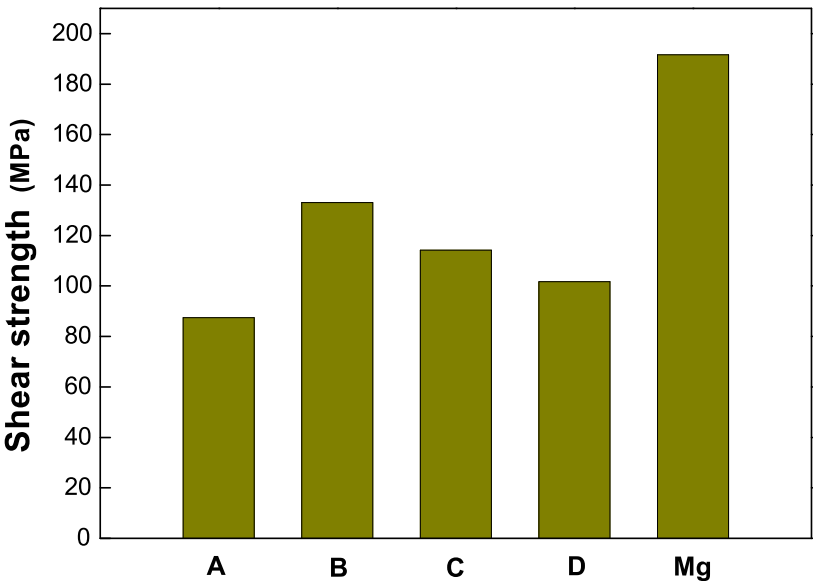

Fig. 6 Shear strength of the joints obtained by different experiments 
Zn were forced to form a liquid alloy at a high temperature on the reaction layer, which partly denuded the steel and caused the slight melting steel. Moreover, the melted magnesium alloy formed a melt-brazed layer with the $\mathrm{Zn}$ layer under the wetting and spreading effect of the rapid heating and solidification conditions for the coupling arc. In addition, the high thermal conductivity of magnesium alloy contributed to the rapid solidification responsible for the fine and uniform microstructure in the fusion zone, which can be traced in Fig. 4b.

Different alloy elements diffuse and react mutually in the BC-MIG process to form solid solution phases, and then the reaction layer, which directly determines the welding quality of $\mathrm{Mg} / \mathrm{Fe}$ joints. The EDS line scan analysis was conducted to reveal the concentration fluctuation of main elements along the reaction layer between magnesium alloy and steel. Figure 5b, c present the EDS line scanning results corresponding to the interfaces shown in Fig. 5a. It is observed in Fig. 5b that element $\mathrm{Mg}$ declined sharply in the interface, while the distribution of element $\mathrm{Fe}$ was the opposite. In Fig. 5c, elements $\mathrm{Zn}$ and $\mathrm{Al}$ diffused into the interface layer where leveling phenomenon can be observed, which suggested that $\mathrm{Mg}-\mathrm{Zn}$ and $\mathrm{Fe}-\mathrm{Al}$ phases were formed at the interface. The content of element $\mathrm{Mn}$ soared in the region close to steel, which indicated $\mathrm{Fe}-\mathrm{Mn}$ intermetallic compounds were likely to form.

It was found in Fig. 5a through the quantitative analysis of chemical compositions by EDS that position A consisted of 48.55 at $\% \mathrm{Mg}, 22.02$ at\% $\mathrm{Zn}, 9.11$ at\% $\mathrm{Al}$, and 18.99 at $\% \mathrm{Fe}$, while position B contained 33.42 at $\% \mathrm{Mg}$, 4.85 at $\% \mathrm{Zn}, 13.03$ at $\% \mathrm{Al}$, and 47.09 at\% Fe. Based on the $\mathrm{Mg}-\mathrm{Zn}$ and $\mathrm{Fe}-\mathrm{Al}$ binary diagram, it was, therefore, identified as eutectic structure $(\alpha-\mathrm{Mg}+\mathrm{MgZn})$ at position A, which was reported by Ma et al. [18], and the intermetallic compounds at position B was indexed as solid solution $\mathrm{Fe}(\mathrm{Al})$. The $\mathrm{Mg}-\mathrm{Zn}$ phases were concentrated on the $\mathrm{Mg}$ side of the reaction layer, while the $\mathrm{Fe}-\mathrm{Al}$ intermetallic compounds were supposed to be on the steel side of interface. It can thereby be concluded that the formation of intermetallic compounds in the different regions of weld bead is the result of element diffusion with different heat inputs. Since the melting points of $\mathrm{Zn}$ and $\mathrm{Mg}$ are much lower than that of $\mathrm{Fe}$, the molten $\mathrm{Zn}$ layer firstly reacts with element $\mathrm{Mg}$, and $\mathrm{Mg}-\mathrm{Zn}$ phases gathering in the reaction layer on the $\mathrm{Mg}$ side. Galvanized steel melted slightly due to the excessive heat input, and formed intermetallic compounds with $\mathrm{Fe}-\mathrm{Al}$ phases. As the thickness of the reaction layer consisted of intermetallic compounds has its effect primarily on the mechanical properties of welded joints, and due to that $\mathrm{Zn}$ layer and molten brazing filler completely melt and reacted faster than the diffusion speed of element Fe [19], so the thickness is mainly depended on the reaction temperature and thickness of $\mathrm{Zn}$-coated steel in the BC-MIG process. As shown in Fig. 5d, the scanning point mainly consisted of 67.06 at $\% \mathrm{Mg}$ and 26.63 at $\% \mathrm{Zn}$, which implied it was an $\mathrm{Mg}-\mathrm{Zn}$ phase which turns out to be $\mathrm{Mg}_{7} \mathrm{Zn}_{3}$.

\subsection{Joint Efficiency}

As shown in Fig. 6, the maximum calculated shear strength of lap joints is $133.02 \mathrm{MPa}$. The joint efficiency used in Ref. [20] is introduced to evaluate the mechanical properties of lap joints, and it represents the ratio of maximum capacity force to the force required to fracture the base

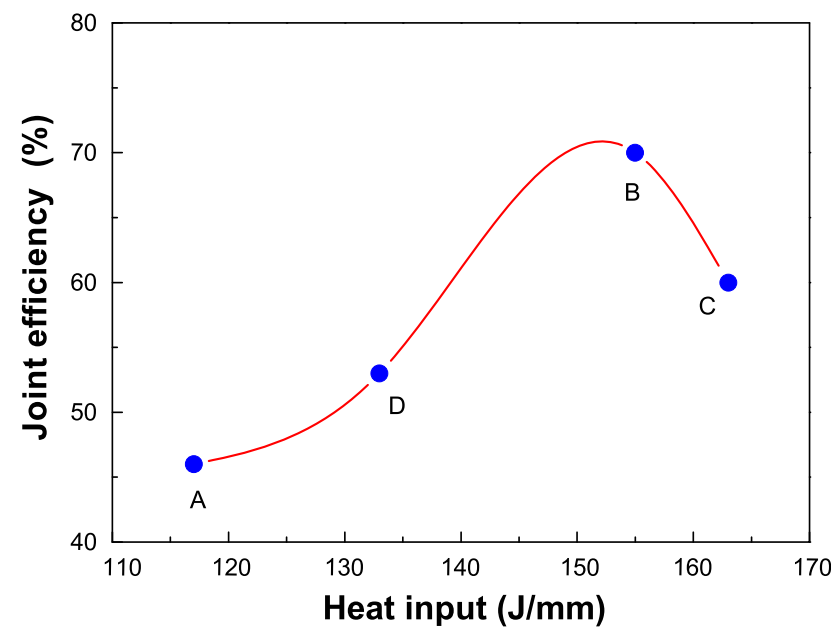

Fig. 7 Effect of heat input on the joint efficiency

Table 3 Calculated welding parameters for different welding experiments

\begin{tabular}{lllllllll}
\hline Experiment & $\begin{array}{l}\text { Welding } \\
\text { current }(\mathrm{A})\end{array}$ & $\begin{array}{l}\text { Welding } \\
\text { voltage }(\mathrm{V})\end{array}$ & $\begin{array}{l}\text { Welding speed } \\
(\mathrm{cm} / \mathrm{min})\end{array}$ & $\begin{array}{l}\text { Heat input } \\
(\mathrm{J} / \mathrm{mm})\end{array}$ & $\begin{array}{l}\text { Weld area } \\
\left(\mathrm{mm}^{2}\right)\end{array}$ & $\begin{array}{l}\text { Maximum } \\
\text { tension Fm }(\mathrm{N})\end{array}$ & $\begin{array}{l}\text { Tensile } \\
\text { strength }(\mathrm{MPa})\end{array}$ & $\begin{array}{l}\text { Joint } \\
\text { efficiency } \\
(\%)\end{array}$ \\
\hline A & 76 & 18 & 70 & 117 & 24.25 & 2,120 & 87.42 & 45.63 \\
B & 76 & 18 & 53 & 155 & 21.50 & 2,860 & 133.02 & 70.01 \\
C & 76 & 19 & 53 & 163 & 24.00 & 2,740 & 114.17 \\
D & 76 & 19 & 65 & 133 & 24.00 & 2,440 & 101.67 & 53.06 \\
\hline
\end{tabular}



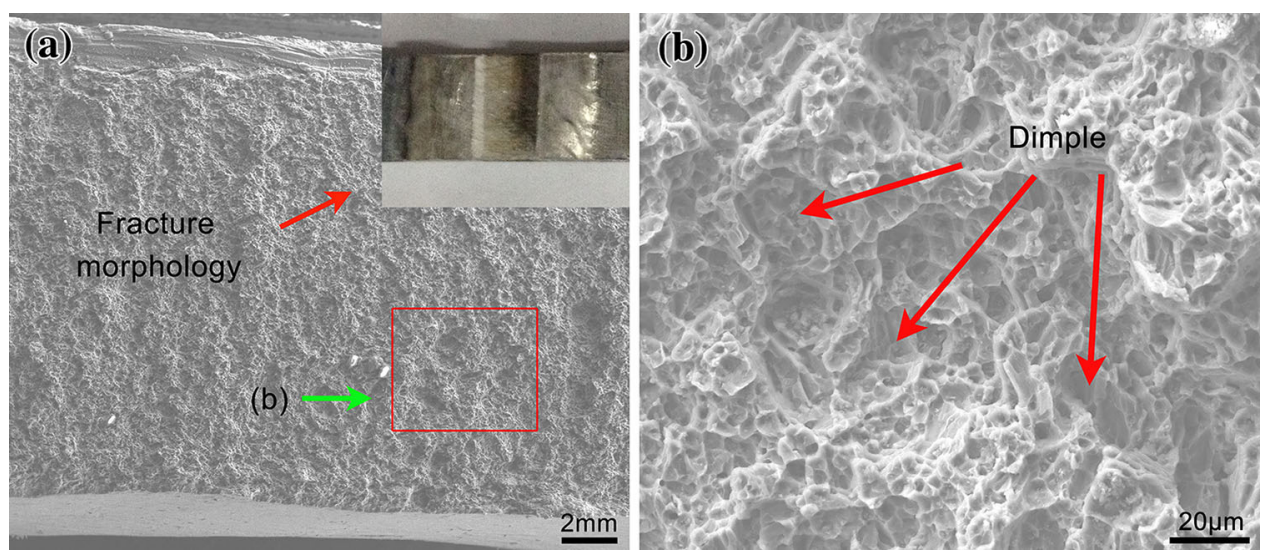

Fig. 8 SEM images of the fracture surface $\mathbf{a}$ and the magnified image $\mathbf{b}$ of the marked region in $\mathbf{a}$

material. The force required to fracture the magnesium alloy can be expressed as:

$\eta=\frac{F_{\mathrm{m}}}{A_{\mathrm{w}} T_{\mathrm{s}}} \times 100 \%$,

where $F_{\mathrm{m}}$ is the maximum tensile capacity of a welded joint, $A_{\mathrm{w}}$ is the cross-sectional area of magnesium alloy base metal, and $T_{\mathrm{s}}$ is the tensile strength of magnesium alloy.

Table 3 gives the calculation results of joint efficiency under the different heat inputs. As shown in Fig. 7, the joint efficiency reached its maximum of about $70 \%$ when the heat input was $155 \mathrm{~J} / \mathrm{mm}$. The joint efficiency tended to increase at first and then to reduce with the increase of heat input because a lower heat input caused a lower interface temperature, which led to the poor wetting and spreading of molten magnesium alloy, thereby causing incomplete fusion. Consequently, the joints had a poor tensile strength at a low heat input. On the contrary, a higher heat input resulted in a higher interface temperature, which brought about the excessive melting of steel and the serious evaporation of $\mathrm{Mg}\left(T_{\text {vap }}=1,090{ }^{\circ} \mathrm{C}\right)$ and $\mathrm{Zn}\left(T_{\text {vap }}=908^{\circ} \mathrm{C}\right)$. There was no intersolubility and reaction between elements $\mathrm{Mg}$ and $\mathrm{Fe}$, so weld cracking occurred easily at the interface which lowered the joint efficiency.

It is presented in Fig. 8a that the fractured surface was coarse and dark gray, representing morphology of ductile fracture. In Fig. 8b, dimples were distributed on the fracture surface, representing a ductile fracture mode. As shown in Fig. 8a, a specimen cracked in the location of weld metals, which implied that the strength of interface was excellent for the bonding of reaction layer.

\subsection{Hardness}

It is shown in Fig. 9 that the average hardness of steel and $\mathrm{Mg}$ were 140 and $60 \mathrm{HV}$, respectively. The hardness

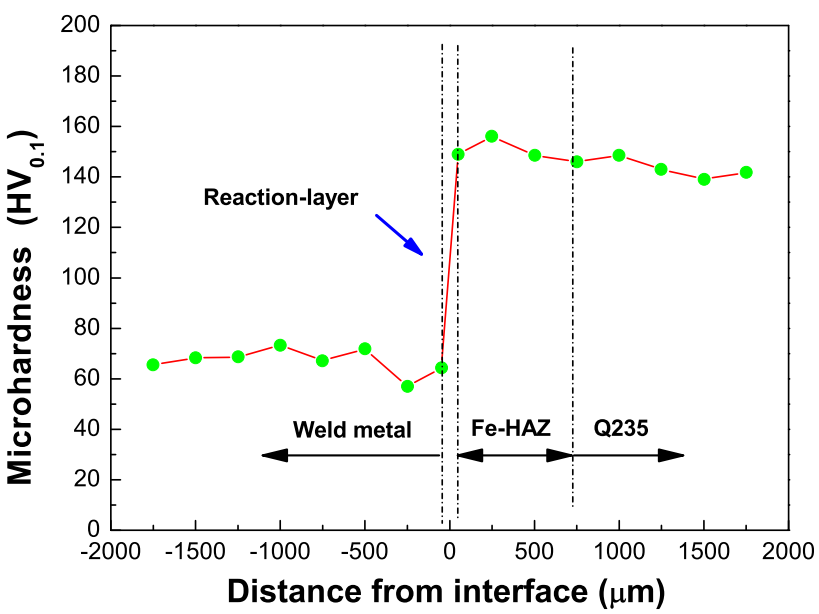

Fig. 9 Micro-hardness profile along the middle section of the lap joint

increased sharply along the interface from weld metal to steel, because elements mutually diffused and the content of elements changed in the reaction layer. The contents of alloy elements have a significant effect on the hardness of interface. With the increase of elements $\mathrm{Fe}, \mathrm{Zn}$, and $\mathrm{Al}$, the hardness of magnesium alloy increases in the material [21]. Element concentration increased as the distance from the steel interface decreased, which resulted in a higher hardness in the interface. As shown in Fig. 9, there was a slight increase in hardness in the heat-affected zone (HAZ) of steel, which has much to do with the microstructural transformation of steel due to rapid heating and cooling in the welding process.

\section{Conclusions}

(1) The stability of welding process and the transfer of droplet can be improved by adding a bypass arc, and 
spatter can be avoided in the BC-MIG process, and the $\mathrm{BC}-\mathrm{MIG}$ process is a stable process, which can be used to achieve the reliable joining of $\mathrm{Mg}$ alloy to galvanized steel with a good weld appearance.

(2) The joint interface is an extremely thin and continuous layer of intermetallic compounds, of which the thickness mainly depends on the reaction temperature and the thickness of $\mathrm{Zn}$-coating. It is supposed that $\mathrm{Mg}-\mathrm{Zn}$ phase is near the side of $\mathrm{Mg}$ alloy, while the $\mathrm{Fe}-\mathrm{Al}$ phase is near the steel side.

(3) The joint efficiency tends to increase at first and then to decrease with the increase of heat input in the welding process. The joint efficiency reaches its maximum of about $70 \%$ when the heat input is $155 \mathrm{~J} /$ $\mathrm{mm}$. Cracking occurs at the location of welded metals. There are some dimples on the fracture surface, representing the morphology of ductile fracture.

(4) A rapid increase in hardness occurred near the steel interface, which is related to the diffusion and distribution of elements on the interface. Element concentration increases as the distance from the steel interface decreases, which results in a higher hardness in the interface.

Acknowledgments This work was financially supported by the National Natural Science Foundation of China (No. 51005049).

\section{References}

[1] B.L. Mordike, T. Ebert, Mater. Sci. Eng. A 302, 37 (2001)
[2] W. Elthalabawy, T. Khan, J. Mater. Sci. Technol. 27, 22 (2011)

[3] S.J. Wang, G.L. Qin, Y.H. Su, Acta Metall. Sin. (Engl. Lett) 26, 177 (2013)

[4] Y.N. Wei, J.L. Li, J.T. Xiong, F. Huang, F.S. Zhang, Mater. Des. 33, 111 (2012)

[5] C. Schneider, T. Weinberger, J. Inoue, T. Koseki, N. Enzinger, Sci. Technol. Weld. Join. 16, 100 (2011)

[6] W. Xu, D.L. Chen, L. Liu, H. Mori, Y. Zhou, Mater. Sci. Eng. A 537, 11 (2012)

[7] L. Liu, L. Xiao, J.C. Feng, Y.H. Tian, S.Q. Zhou, Y. Zhou, Metall. Mater. Trans. A 41, 2651 (2010)

[8] W. Elthalabawy, T. Khan, Mater. Charact. 61, 703 (2010)

[9] W. Elthalabawy, T. Khan, Key Eng. Mater. 442, 26 (2010)

[10] G. Song, G.Y. An, L.M. Liu, Mater. Des. 35, 323 (2012)

[11] X.D. Qi, G. Song, Mater. Des. 31, 605 (2010)

[12] Y.C. Chen, K. Nakata, Mater. Trans. 50, 2598 (2009)

[13] T. Tachibana, S. Hojo, S. Iwatani, T. Quart, S. Nakagawa, J. Jpn. Weld. Soc. 27, 183 (2009)

[14] L.M. Liu, X. Zhao, Mater. Charact. 61, 1279 (2008)

[15] Y.G. Miao, D.F. Han, J.Z. Yao, F. Li, Sci. Technol. Weld. Join. 15, 97 (2010)

[16] Y.G. Miao, D.F. Han, J.Z. Yao, F. Li, Mater. Des. 31, 3121 (2010)

[17] Y.M. Zhang, M. Jiang, W. Lu, Weld. J. 83, 39 (2004)

[18] L. Ma, D.Y. He, X.Y. Li, J.M. Jiang, Mater. Lett. 64, 596 (2010)

[19] L.Q. Li, C.W. Tan, Y.B. Chen, W. Guo, F. Song, Mater. Des. 43, 59 (2013)

[20] S. Jana, Y. Hovanski, G.J. Grant, Metall. Mater. Trans. A 41, 3173 (2010)

[21] Y.X. Gu, Particular Engineering Materials Welding, 1st edn. (Liaoning Science and Technology Press, Shenyang, 1998), p. 72. (in Chinese) 